\title{
Neurotizaciones Sensitivas en Cirugía de la Mano
}

\section{Sensitive Neurotizations in Hand Surgery}

F. Martínez Martínez ${ }^{1} \quad$ B. Níguez Sevilla ${ }^{2} \quad$ S. Toledo García ${ }^{3} \quad$ J. García García ${ }^{3} \quad$ J. García Navarro ${ }^{3}$

A. Izquierdo Robledano ${ }^{3}$ A. Gimenez $\operatorname{Ros}^{3}$

1 FEA de Cirugía Ortopédica y Traumatología del Hospital Clínico Universitario Virgen de la Arrixaca, Murcia, España

2 FEA de Cirugía Ortopédica y Traumatología del Hospital Santa Lucía. Cartagena, Murcia, Spain

${ }^{3}$ Médico Residente de Cirugía Ortopédica y Traumatología del

Hospital Clínico Universitario Virgen de la Arrixaca, Murcia, España

\begin{abstract}
Address for correspondence Francisco Martínez Martínez, FEA de Cirugía Ortopédica y Traumatología del Hospital Clínico Universitario Virgen de la Arrixaca, C/ Canovas del Castillo n7- $4^{\circ}$ a. 30003-Murcia, Spain (e-mail: fmtnez@gmail.com).
\end{abstract}

Rev Iberam Cir Mano 2017;45:136-145.

\section{Resumen \\ Palabras-clave \\ - nervio mediano \\ - nervio cubital \\ - neurotización sensitiva}

\section{Abstract \\ Keywords \\ - median nerve \\ - ulnar nerve \\ - sensitive neurotization}

La lesión de los nervios mediano y cubital puede ocasionar daños permanentes y tiene consecuencias devastadoras. Los accidentes con instrumentos cortantes en ambiente laboral o doméstico y las lesiones del plexo braquial, constituyen las causas más frecuentes. En los casos de lesión del nervio mediano, recuperar la sensibilidad de la "pinza” (borde cubital del pulgar y radial del índice), es esencial para la reeducación de la función motora e incluso, puede considerarse un requisito previo. Asimismo, la lesión del nervio cubital, conlleva a déficit de sensibilidad del borde medial de la mano y produce falta de soporte para la manipulación con la pinza. En ambos casos, la mano está expuesta a traumatismos, heridas, quemaduras, etc. En el momento de la lesión y siempre que sea posible, debe realizarse una reparación primaria del nervio. Las avulsiones, las lesiones proximales y los grandes defectos nerviosos, obligan a una reconstrucción secundaria cuando el paciente se ha recuperado de la lesión aguda. Este estudio objetiva una actualización de la literatura.

Median and ulnar nerves injuries may cause permanent damage and have devastating consequences. The most frequent causes are accidents with cutting tools in work or domestic environment and brachial plexus lesions. In the event of median nerve injury, the recovery of pincer grasp sensitivity (ulnar edge of the thumb and radial edge of the index finger) is essential for the motor function reeducation, and may be even considered a prerequisite. Likewise, ulnar nerve lesions imply sensory loss in the medial edge of the hand and cause lack of support for the pincer grasp. In both cases the hand is exposed to trauma, wounds, burns, etc. Whenever possible a primary nerve repair must be performed after injury. A secondary repair is required when the patient has recovered from an acute injury due to an avulsion, a proximal lesion of a large nervous defect. This study is an update of the literature. received

September 14, 2017

accepted

September 25, 2017

published online

November 22, 2017
DOI https://doi.org/

10.1055/s-0037-1608626. ISSN 1698-8396.
Copyright $\odot 2017$ Thieme Revinter

Publicações Ltda, Rio de Janeiro, Brazil
License terms

(c) $(1) \$$ 


\section{Introducción}

La lesión de los nervios mediano y cubital puede ocasionar daños permanentes y tiene consecuencias devastadoras. Los accidentes con instrumentos cortantes en ambiente laboral o doméstico y las lesiones del plexo braquial, constituyen las causas más frecuentes.

En los casos de lesión del nervio mediano, ${ }^{1}$ recuperar la sensibilidad de la "pinza" (borde cubital del pulgar y radial del índice), es esencial para la reeducación de la función motora e incluso, puede considerarse un requisito previo. Asimismo, la lesión del nervio cubital, ${ }^{2}$ conlleva un déficit de sensibilidad del borde medial de la mano y produce falta de soporte para la manipulación con la pinza. En ambos casos, la mano está expuesta a traumatismos, heridas, quemaduras, etc.

En el momento de la lesión y siempre que sea posible, debe realizarse una reparación primaria del nervio. Las avulsiones, las lesiones proximales y los grandes defectos nerviosos, obligan a una reconstrucción secundaria ${ }^{3}$ cuando el paciente se ha recuperado de la lesión aguda.

La primera neurotización sensitiva de la mano fue descrita por Harris ${ }^{4}$ en 1921, desde entonces, figuran en la bibliografía solamente unos veinte artículos sobre el tema. La preocupación por la restauración de la función motora, ha dejado en un segundo plano la recuperación sensitiva, siendo ambas complementarias.

Las ventajas de las transferencias nerviosas son diversas, entre ellas tenemos:

- Se pueden usar en situaciones originalmente insalvables como lesiones del plexo.

- Minimizan el tiempo de reinervación, tanto sensorial como motora.

- La cirugía se realiza en territorios distintos a los lesionados.

Respecto a las transferencias nerviosas sensitivas, hay que tener en cuenta que permiten restaurar la sensibilidad en zonas críticas con ramas de áreas nerviosas no críticas y se deben realizar lo más distal posible. Entre sus indicaciones tenemos ${ }^{5}$

- Lesiones del plexo braquial proximal donde no es reparable.

- Lesiones proximales de nervios periféricos con una distancia larga hasta la zona de re inervación

- Zonas cicatriciales con riesgo de lesión de estructuras anatómicas importantes

- Pérdida de segmentos nerviosos

- Lesiones nerviosas parciales con afectación funcional

- Presentación tardía de la lesión en la que no hay tiempo suficiente para reinervar la zona distal mediante injerto

- Déficits sensitivos en zonas críticas

Además, hemos de tener en cuenta que la restauración sensitiva es un requisito para la restauración de la función motora. ${ }^{1}$

La literatura recoge varios tipos de neurotizaciones sensitivas para la pinza ${ }^{2,6,7}$ y para el borde medial de la mano. ${ }^{2,6}$ En el primer caso, cuando ambos nervios, mediano y cubital, están afectados, la neurotización sensitiva de la pinza se lleva a cabo con las ramas sensitivas dorsales de la primera comisura (n. radial). Cuando el nervio cubital no está afectado, se pueden utilizar el nervio digital común de la cuarta comisura y la rama sensitiva dorsal del nervio cubital.

Brunelli, ${ }^{1}$ transfiere en doce casos, las ramas dorsales del nervio radial para neurotizar la pinza y utilizando el sistema de clasificación Highet-Zachary (S1: Anestesia; S2: Dolor. S2 + : Tinnel; S3: Recuperación de dolor y tacto. S3 + : Discriminación entre dos puntos $>1 \mathrm{~cm}$; S4: Recuperación de dolor y tacto con discriminación entre 2 puntos $<1 \mathrm{~cm}$ ), comunica los siguientes resultados: seis casos obtuvieron puntuación S2 + , cuatro S2, uno S y otro S0. En todos los casos, realiza la disección intraneural del nervio mediano y transfiere de dorsal a palmar las ramas sensitivas radiales, neurotizando la pinza a nivel de la palma.

Además, en dos casos utiliza el nervio digital común de la cuarta comisura (n. cubital), obteniendo S2+ y S1, respectivamente. En otros dos casos, realiza la transferencia de las ramas dorsales sensitivas del nervio cubital, obteniendo en ambos S0.

Otros autores, tales como Bertelli, ${ }^{2}$ neurotizan los nervios digitales del borde cubital del pulgar y radial del índice con las ramas dorsales del nervio radial a nivel de la primera falange respectivamente. En ocho casos comunica la recuperación completa de la sensibilidad de la pinza. La habilidad para localizar el tacto se adquiere en todos los pulgares y en la mitad de los índices. Ningún paciente presentó dolor o hiperalgesia (medida mediante monofilamentos de SemmesWeinstein).

En los casos de lesión aislada del nervio cubital, la neurotización sensitiva del borde medial de la mano, se lleva a cabo con el nervio mediano ${ }^{1,2}$ o con el nervio cutáneo antebraquial lateral. ${ }^{2}$ En el primer caso, se utilizan la rama cutáneo palmar, las ramas cutáneas, el nervio digital cubital del índice, el nervio digital radial del tercer dedo o el nervio digital radial del cuarto dedo. En el segundo caso, la neurotización está descrita en años y a veces utilizando injerto de nervio sural.

Bertelli, ${ }^{2}$ en un artículo reciente, comunica la neurotización del borde medial de la mano en ocho casos. En tres de ellos, utiliza la rama cutáneo palmar del n. mediano, obteniendo un resultado S3. En otros tres casos, utiliza las ramas cutáneas del n. mediano, consiguiendo en dos casos S3+y en un caso S3. Finalmente, utiliza el nervio digital cubital del índice, obteniendo S3.

\section{Neurotizaciones Para la Pinza}

Las lesiones proximales del nervio mediano producen un déficit sensitivo en la palma de la mano y dedos que afectan a la función de la pinza. ${ }^{8}$

La reparación proximal tiene resultados pobres en cuanto a la recuperación de la sensibilidad en estas zonas debido a la distancia entre la zona de lesión y los receptores cutáneos en los dedos, por lo que se han descrito técnicas enfocadas a aproximar la zona de reparación nerviosa a los órganos sensitivos terminales utilizando como donantes ramas sensitivas de los nervios radial y cubital.

Harris $(1921)^{4}$ fue el primero en describir una técnica de neurotización sensitiva, que consistía en transferir la rama 
superficial del nervio radial a nivel de la muñeca. Posteriormente, Turnbull $(1984)^{9}$ emplea la técnica en cuatro casos, con recuperación parcial de la sensiblidad, sin cambios en la revisión a 14 años. ${ }^{10}$ Sunderland ${ }^{11}$ propone evitar la denervación completa del área sensitiva del nervio radial en la mano, ya que el territorio radial puede extenderse hacia la zona volar del pulpejo del pulgar, y utiliza como alternativa las ramas distales sensitivas del nervio cubital.

Bedeschi $(1983)^{12}$ obtiene resultados satisfactorios utilizando la técnica descrita por Sunderland en dos casos, y describe la utilización de las ramas sensitivas distales del nervio radial para el dorso de segundo y tercer dedos en el segundo espacio intermetacarpiano, dejando así intacta la rama dorsal del primer dedo.

Brunelli y col. ${ }^{1}$ también describen en 2004 la utilización de las ramas dorsales sensitivas del nervio radial, realizando la neurotización a nivel de la primera comisura o de la muñeca, según lo descrito más abajo.

A continuación, resumimos las técnicas descritas para restaurar la sensibilidad para la pinza en función de las ramas nerviosas utilizadas.

\section{Nervio Radial: Ramas Sensitivas Dorsales del Primer Espacio}

- Neurotización a nivel de la primera comisura (Brunelli) La técnica descrita por Brunelli consiste en realizar una incisión en $\mathrm{V}$ en el primer espacio interdigital, creando un flap cutáneo que se retrae hacia dorsal. Se identifican las ramas digitales cubital del primer dedo y radial del segundo lo más proximal posible. Posteriormente se identifican las ramas sensitivas del nervio radial para las zonas del dorso del primer y segundo dedos, y divididas lo más distal posible, y se realiza una sutura término-terminal con las ramas digitales correspondientes (-Fig. 1).
- Neurotización a nivel de la muñeca (Brunelli) Si las condiciones de la piel en la primera comisura no permiten realizar la técnica anterior, la neurotización se realiza a nivel de la muñeca. Se realiza una incisión dorsal entre los extensores largo y corto del pulgar para localizar las ramas sensitivas del nervio radial. Mediante una segunda incisión en la zona palmar de la muñeca entre el flexor carpis radialis y el palmar largo se accede al nervio mediano. Se realiza una disección intraneural y siguiendo el mapa de Sunderland para la distribución fascicular ${ }^{13}$ se identifican y disecan los fascículos para los colaterales cubital del pulgar y radial del índice. Las ramas radiales dorsales se pasan subcutáneamente hacia anterior, donde se realiza la sutura con el extremo proximal de los fascículos del nervio mediano previamente disecados (-Fig. 2).

- Neurotización a nivel de F1 Bertelli y col. ${ }^{14}$ presentan en 2010 una serie de ocho pacientes con lesiones aisladas del nervio mediano a nivel del codo o proximal a este, en las que realizan una neurotización a nivel de F1 con las ramas sensitivas radiales del primer espacio. Esta técnica parte de la base de realizar la Neurotización lo más distal posible para así disminuir los errores en la ubicación del estímulo sensitivo. Su hipótesis es que al estar los territorios sensoriales dador y receptor más cerca, la adaptación cerebral para la identificación del estímulo sensorial se facilita. Obtuvieron recuperación de la sensibilidad en todos los casos, con una locognosia correcta en todos los pulgares y cuatro de los índices.

Previamente a la cirugía, se identifica el límite de la zona con déficit sensitivo mediante monofilamentos de SemmesWeinstein, así como el territorio sensitivo radial en el pulgar e índice para asegurar la viabilidad de los nervios dadores.

La técnica quirúrgica consiste en realizar una incisión en $\mathrm{V}$ de base volar sobre el borde radial de la falange proximal del
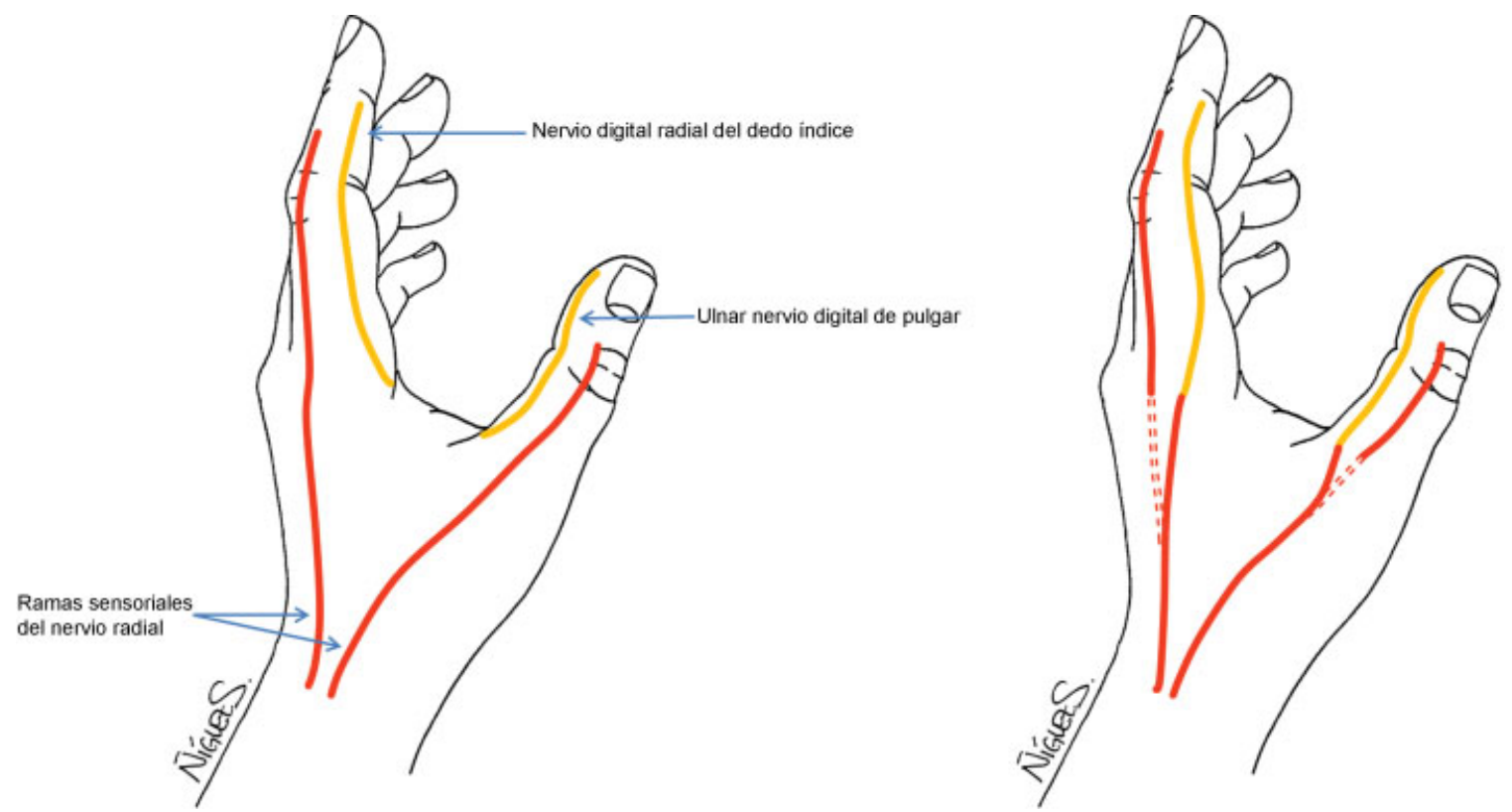

Fig. 1 Transferencia de ramas sensitivas del radial para restablecer la sensibilidad de la pinza. 

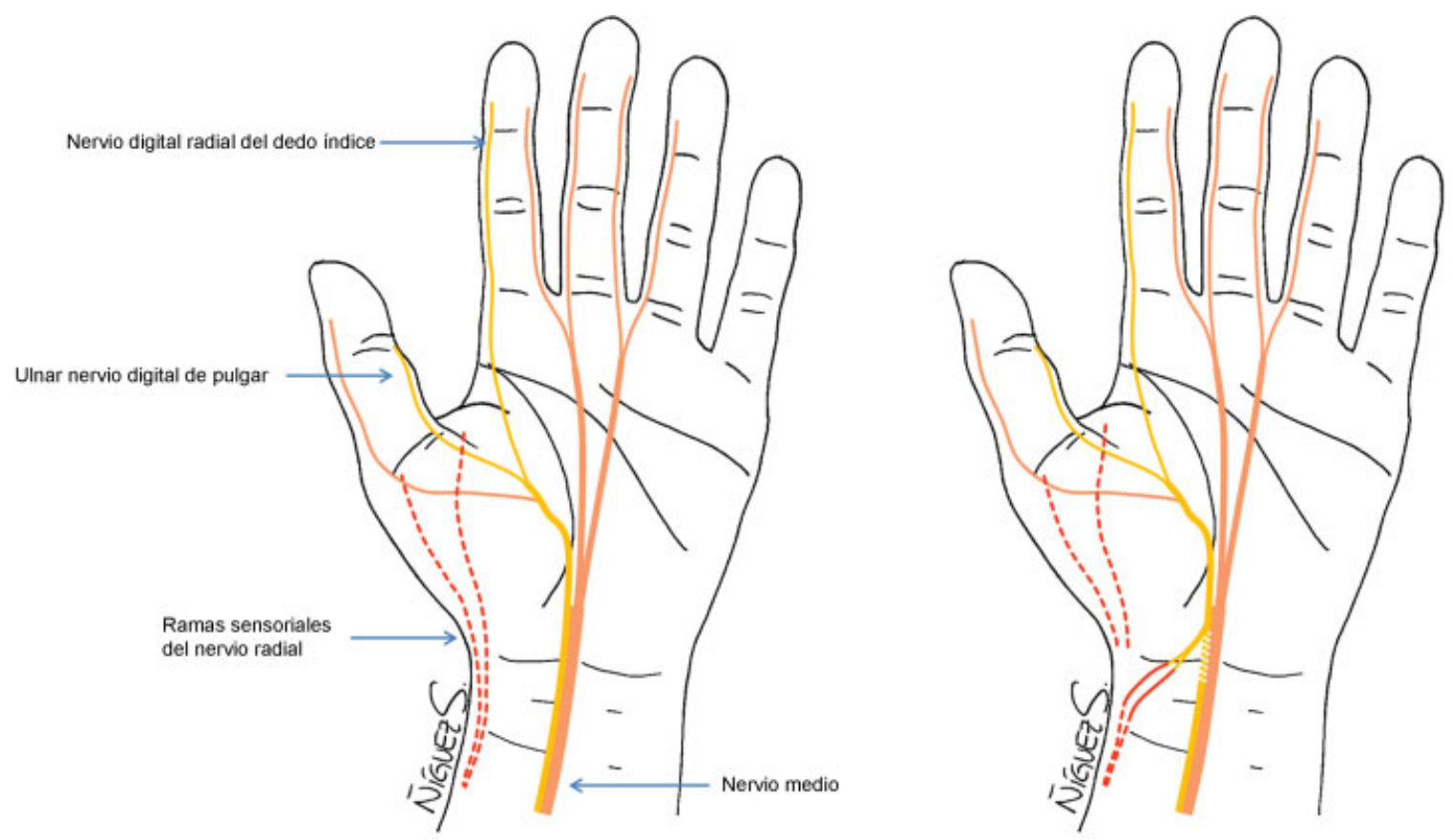

Fig. 2 Transferencia de ramas sensitivas del radial para restablecer la sensibilidad de la pinza a nivel de la muñeca.

índice, y otra sobre el borde cubital de la falange proximal del pulgar. Las ramas dorsales del nervio radial se seccionan al menos $1 \mathrm{~cm}$ proximal a la zona distal de anestesia determinada previamente a la cirugía. El cabo proximal de la rama sensitiva radial se sutura de forma termino-terminal con el cabo distal del nervio digital mediante un monofilamento 9-0 o con Tisucol sin sutura (-Fig. $\mathbf{3}$ ).

\section{Ramas Sensitivas del Nervio Cubital}

Brunelli también describe diferentes técnicas para la transferencia de ramas del nervio cubital a los nervios colaterales digitales del pulgar y del índice.

- Ramas sensitivas dorsales del nervio cubital Se realiza una incisión curva en el borde cubital de la mano, ligeramente dorsal para evitar molestias en la zona de la cicatriz con el apoyo. Las ramas dorsales se pasan subcutáneamente hacia palmar, realizando una incisión sobre el pliegue palmar proximal. Se identifican los nervios colaterales cubital del pulgar y radial del índice para realizar la sutura con las ramas cubitales. (-Fig. 4)

- Nervio digital común de la cuarta comisura Brown y Mackinnon ${ }^{6}$ utilizan esta técnica anteriormente descrita por Brunelli para restaurar la sensibilidad en la primera comisura en lesiones puras del nervio mediano.

El nervio digital común de la cuarta comisura es utilizado para reinervar la piel adyacente del primer y segundo dedo. En la técnica descrita por Brunelli se utiliza un abordaje sobre el pliegue palmar medial a través del cual se identifica el tronco común de la cuarta comisura, así como los colaterales a reinervar. Brown y Mackinnon utilizan un abordaje en zigzag tipo Bruner sobre el túnel del carpo con extensión a la primera y cuarta comisura. El nervio digital común de la cuarta comisura es seccionado a nivel de las cabezas de los metacarpianos y disecado para obtener la longitud necesaria. Los colaterales cubital del primer dedo y radial del segundo se identifican distalmente y se disecan hacia proximal, separándolos cuidadosamente del tronco principal del nervio mediano. Una vez obtenida la longitud adecuada en ambos cabos, se realiza una sutura termino-terminal con una sutura de nylon de 9-0 o Tisucol. Si solo fuera necesario reinervar el índice, se utiliza el nervio colateral cubital del cuarto dedo (- Fig. 5)

\section{Neurotización Intramediano}

En una lesión del tronco superior del plexo braquial (sin afectación por tanto de los fascículos provenientes de C8 y T1), la sensibilidad del tercer espacio intermetacarpiano está conservada, y puede ser transferida a los fascículos afectos del nervio mediano para recuperar la sensibilidad de la pinza.

Brown y Mackinnon ${ }^{6}$ describen la técnica de neurotización con los fascículos para la tercera comisura a los fascículos afectos para el área de la pinza. Refieren obtener una sensibilidad moderada con esa técnica ( 4 a 8 sobre 10 medido con el "Ten Test" ${ }^{15}$ ) aunque prefieren esa técnica a las que utilizan las ramas superficiales del nervio radial o la rama cutánea dorsal del nervio cubital, ya que estos nervios dadores inervan un territorio mayor.

La técnica se realiza a nivel del antebrazo, de manera que se pueden exponer los fascículos dadores y receptores mediante una única incisión. Consiste en realizar una incisión sobre el túnel del carpo extendida hacia el antebrazo cruzando en zigzag el pliegue de la muñeca. Se procede a la apertura del ligamento transverso del carpo para conseguir la exposición del nervio mediano y evitar cualquier compresión que dificulte la regeneración nerviosa. A este nivel los fascículos del nervio mediano pueden ser identificados y disecados hacia proximal. Los correspondientes al primer espacio interdigital deben ser disecados hasta $13 \mathrm{~mm}$ proximal a la estiloides radial, 

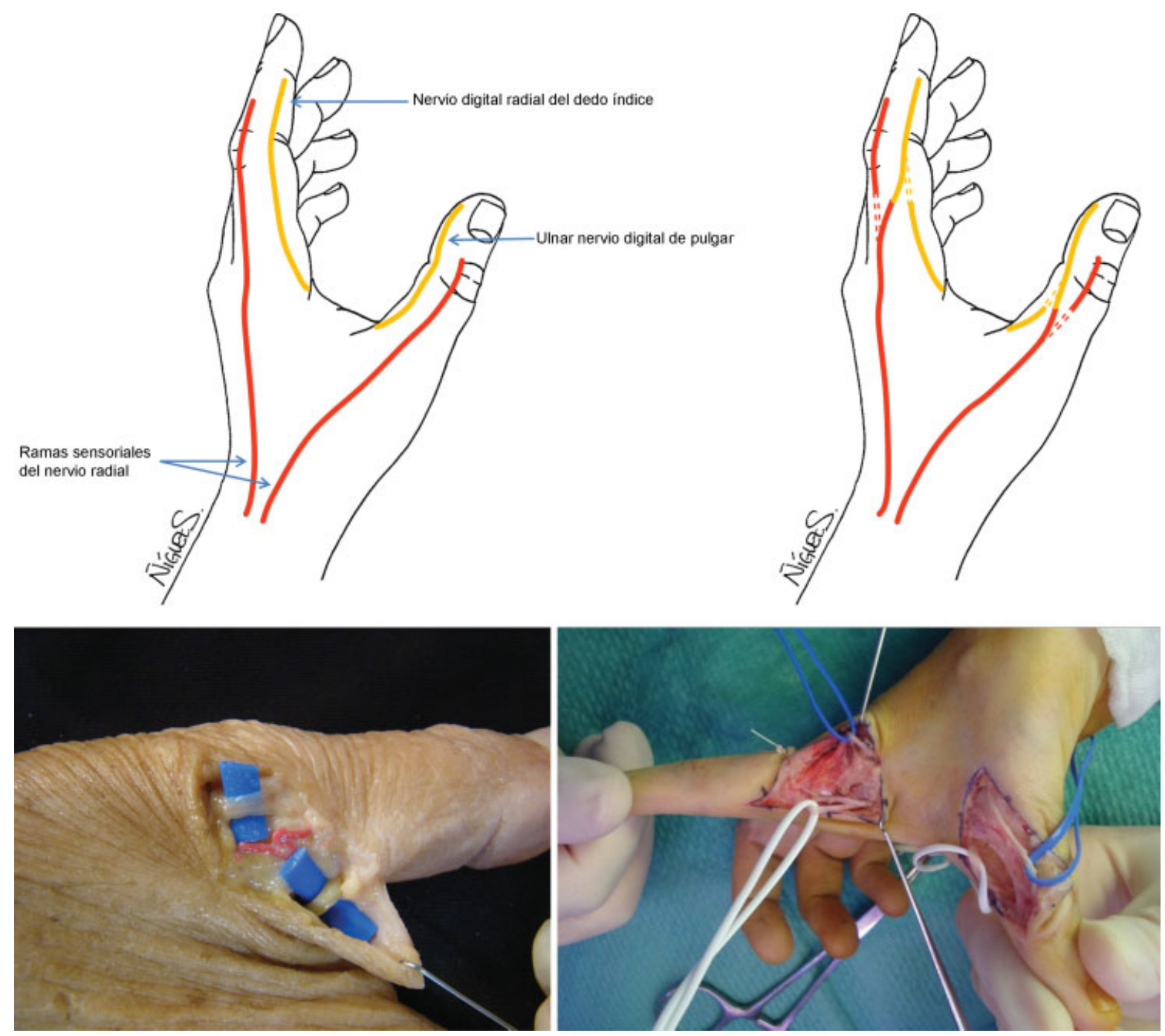

Fig. 3 En la parte superior esquema de la técnica, en la zona media disección anatómica mostrando una rama sensitiva dorsal y nervio colateral cubital pulgar, en la parte inferior del caso clínico.

separando la ramas motora. A nivel de la muñeca se realiza la neurolisis de los fascículos correspondientes del primer y tercer espacio interdigital del resto del nervio, y se realiza una sutura término-terminal entre el cabo proximal del

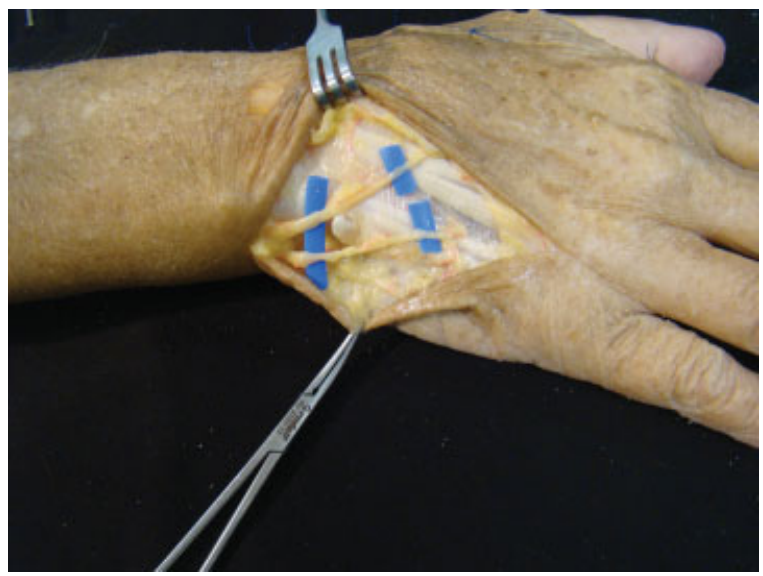

Fig. 4 Disección anatómica de las ramas sensitivas dorsales del nervio cubital. fascículo para el tercer espacio y el cabo distal para el primero ( - Fig. 6). Boyd y col..$^{5}$ añaden el gesto de realizar una sutura término-lateral del cabo distal del fascículo para el tercer espacio con el componente sensitivo principal del nervio cubital para restaurar la sensibilidad en el tercer espacio interdigital.

\section{Triple Transferencia}

Boyd y col. ${ }^{5}$ describen la triple transferencia para reparar los déficits de sensibilidad del nervio mediano. Incisión en tercio distal del antebrazo ampliada a la región del túnel del carpo y canal de Guyon que se abren para evitar neuropatías por compresión. Por un lado, la sensibilidad en el pulgar y primer espacio interdigital se restaura transfiriendo la porción proximal de la rama cutánea dorsal del nervio cubital de forma términoterminal con el borde radial del nervio mediano (fascículos para primer y segundo espacios interdigitales). En segundo lugar, se identifica el fascículo para el tercer espacio y se sutura de forma término-lateral con el tronco sensitivo principal del nervio cubital. En último lugar, se restaura la inervación sensitiva del territorio donante realizando una sutura término-lateral entre el 

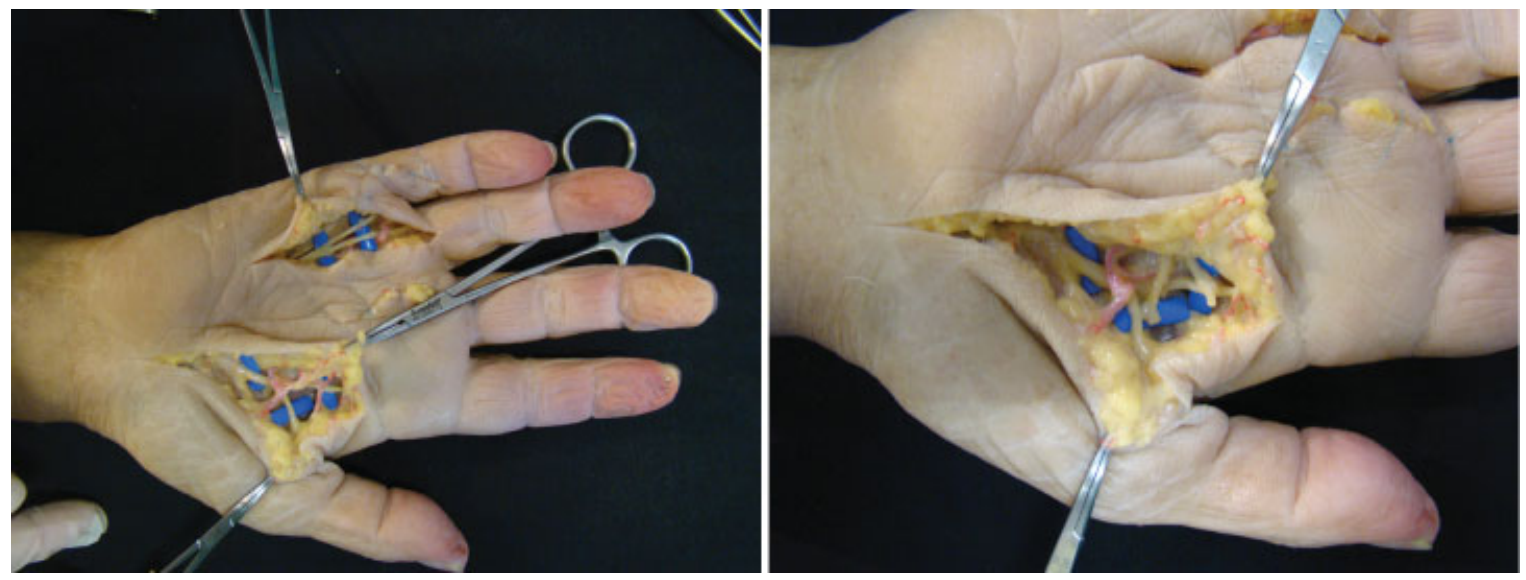

Fig. 5 En la imagen de la izquierda, se aprecia la disección del nervio digital común de la $4^{\circ}$ comisura, en la imagen de la derecha la transferencia subcutánea de las ramas terminales del nervio digital común del $4^{\circ}$ espacio para resensibilizar la pinza.
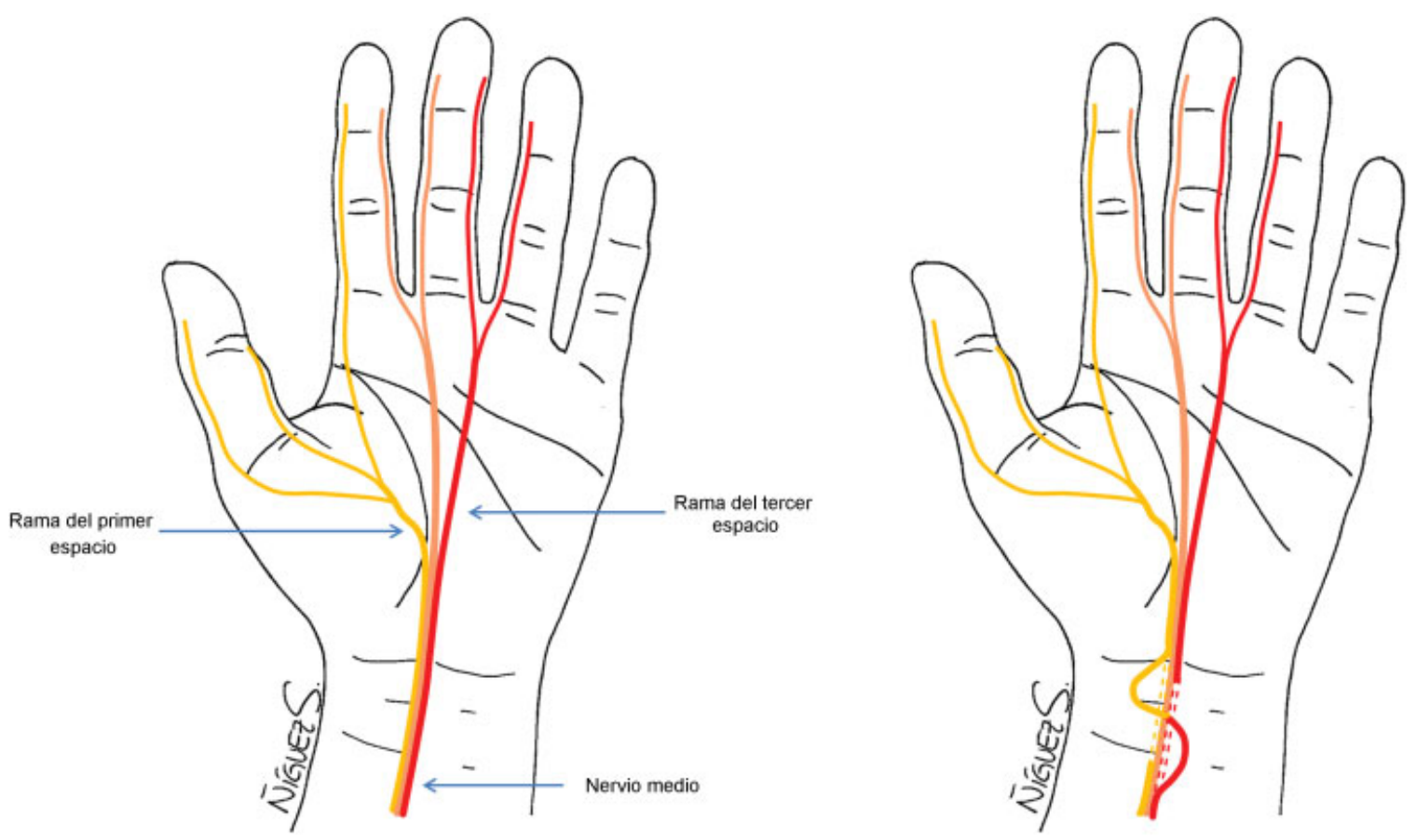

Fig. 6 Transferencia del intramediano: fascículo de tercera a primera comisura.

cabo distal de la rama cutánea dorsal del nervio cubital y la porción sensitiva del nervio cubital (- Fig. 7).

\section{Neurotizaciones Para el Borde Cubital}

Cuando se produce una lesión que provoca la insensibilidad del borde cubital de la mano, se puede beneficiar de la reconstrucción sensitiva. ${ }^{16}$ Es importante intentar restaurar esa sensibilidad porque predispone a diversas lesiones, el borde cubital se usa para apoyar la mano y se pueden producir lesiones de la piel o incluso infecciones. ${ }^{17}$ Según Brown y Mackinnon, ${ }^{16}$ cuando existe un déficit neurológico el objetivo es recuperar la función más que una restauración anatómica. Además, el uso de nervios donantes locales ofrece unos resultados más confiables a corto plazo que las reparaciones con injerto nervioso, y una reconstrucción más funcional que la proporcionada por las transferencias tendinosas. ${ }^{18}$

A continuación, resumimos las técnicas descritas para restaurar la sensibilidad del borde cubital en función de las ramas nerviosas utilizadas.

\section{Transferencia del Nervio Digital Cubital del Tercer Dedo o Radial del Cuarto (Rama del Nervio Mediano) al Nervio Digital Cubital del Quinto Dedo}

En caso de lesión del nervio digital cubital, esa técnica descrita por Brunelli, ${ }^{1}$ es útil para restaurar la sensibilidad en borde cubital del quinto dedo. Para ello se realiza una incisión en " $Z$ " a nivel de la base del tercer o cuarto dedo, según el que se decida usar y procedemos a la disección e identificación del nervio 

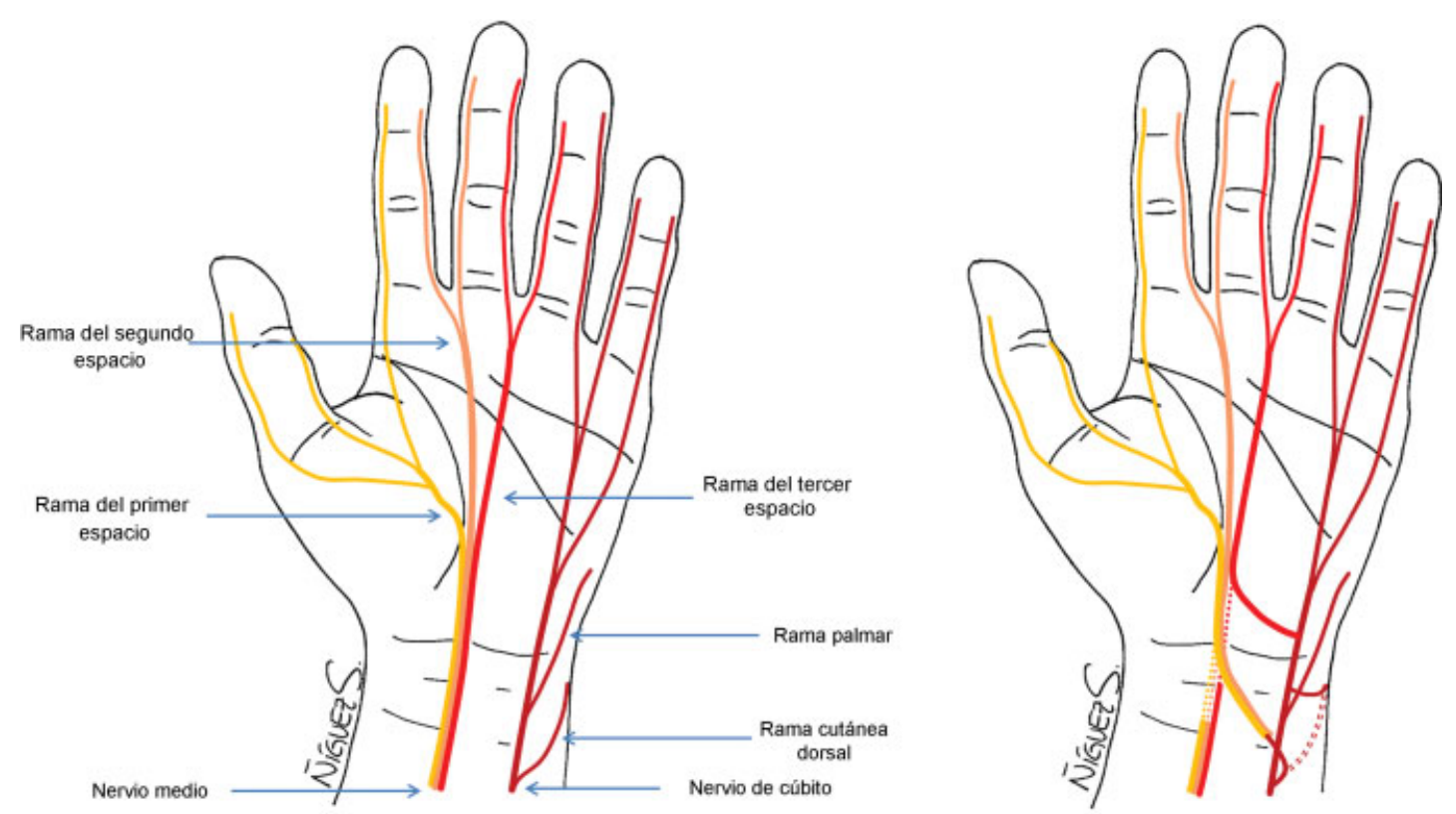

Fig. 7 Transferencia de ramos sensitivos del cubital a mediano: ramo cutáneo dorsal al fascículo de la primera comisura.
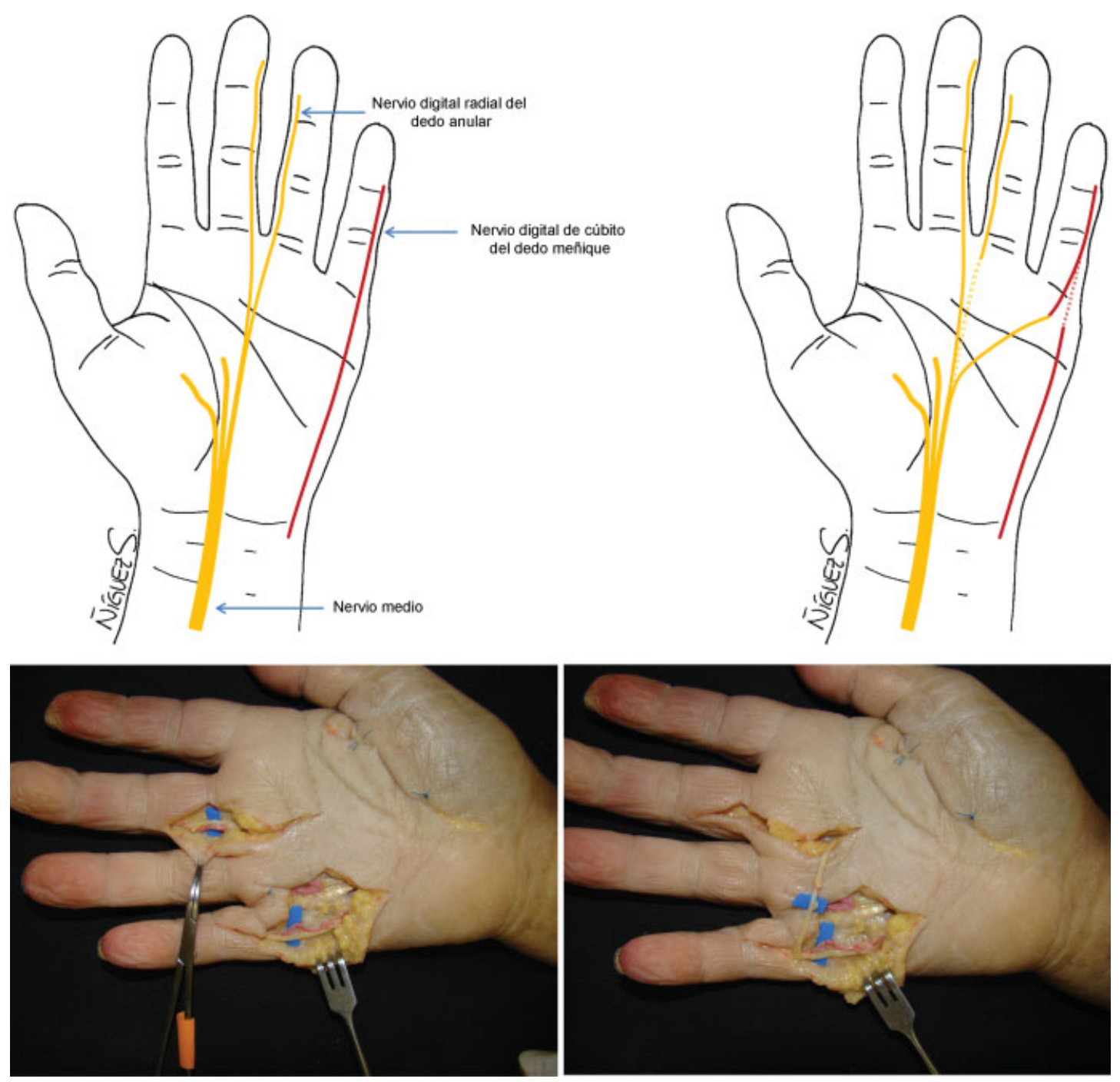

Fig. 8 Transferencia del colateral cubital del $3^{\circ}$ (mediano) al colateral cubital del $5^{\circ}$ (cubital). 

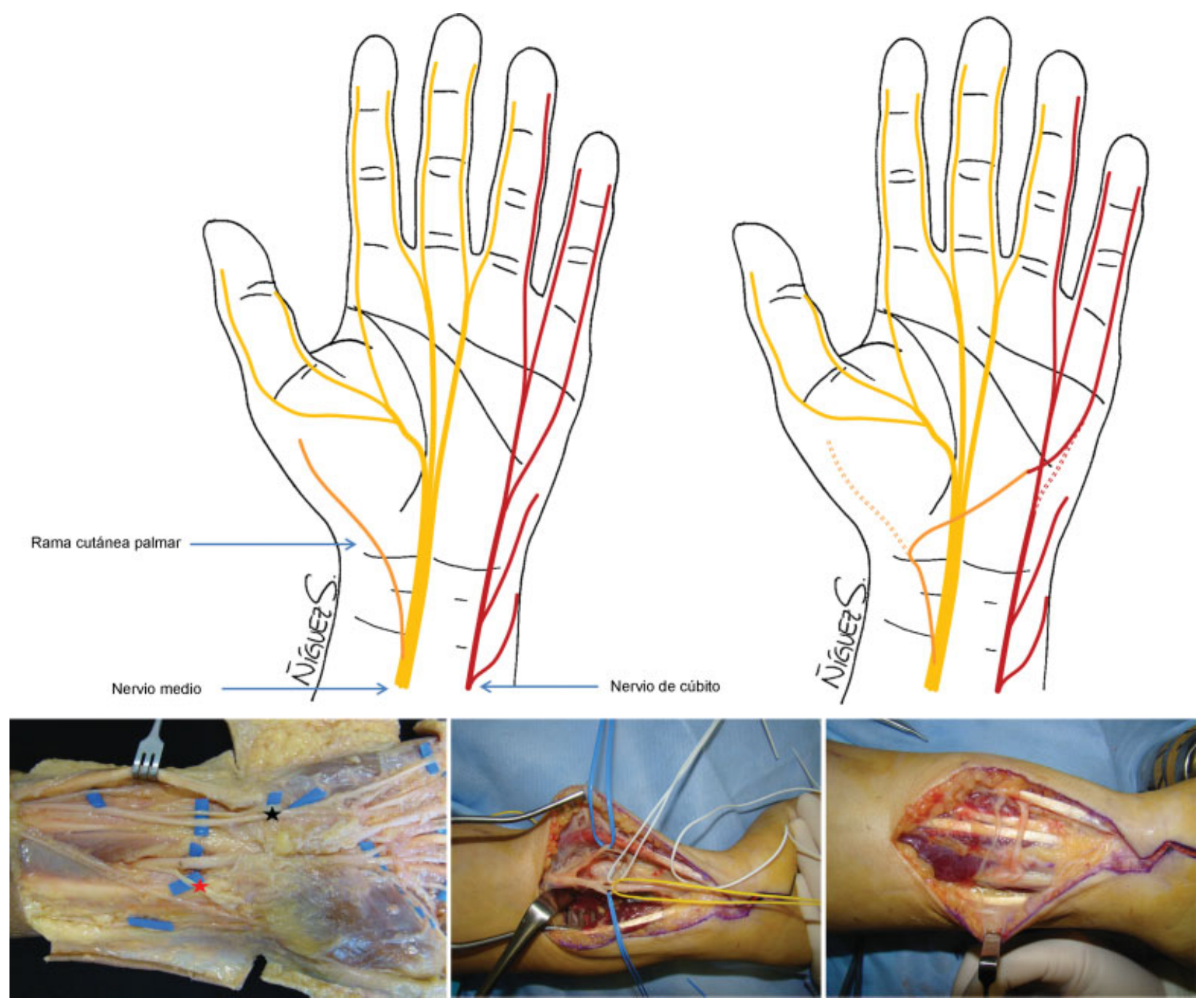

Fig. 9 En la imagen superior esquema de la transferencia. Disección anatómica en zona media donde se ve nervio mediano con rama palmar cutánea (estrella roja) y, nervio cubital con disección intraneural para reinervar fascículo del borde cubital de la mano (estrella negra). En la imagen inferior izquierda, la disección intraneural del nervio cubital y en la inferior derecha, la doble transferencia: motora y sensitiva.

digital. Tras eso, realizamos otra incisión en "Z" a nivel de la base del quinto dedo, sobre el borde cubital, para identificar el nervio colateral cubital. Una vez identificados, procedemos a la sección de ambos, teniendo en cuenta que la neurorafia no debe estar a tensión; y se lleva a través del plano subcutáneo el nervio sano hacia la zona cubital del quinto dedo, y se realiza sutura termino-terminal (- Fig. 8).

\section{Transferencia de la Rama Cutánea Palmar (Nervio Mediano) o Ramas Cutáneas de la Piel al Fascículo Medial Nervio Cubital}

En 2012, Bertelli ${ }^{2}$ presenta una serie de 8 casos con lesión de tipo inferior del plexo braquial, presentando anestesia del lado cubital de la mano con ausencia de la percepción al tacto y del dolor al pellizcar la piel. En ellos realizan una reconstrucción a lo largo del borde cubital de la mano mediante transferencias nerviosas distales, que usarán las ramas cutáneas de la piel (aisladas o combinadas) del nervio mediano si la percepción se conserva en el centro de la palma, y si está ausente hasta la zona distal del túnel del carpo se usará la rama cutánea palmar del nervio mediano. Todos los pacientes del estudio mejoran la sensibilidad.

Respecto a la técnica quirúrgica, se realiza una incisión en "Z" en la palma de la mano para localizar las ramas cutáneas o podemos usar una incisión longitudinal en la zona proximal del túnel del carpo para localizar la rama cutánea palmar del nervio mediano. Posteriormente se realiza disección intraneural del nervio cubital iniciando desde la división del nervio en la palma separando fascículo motor-fascíiculo sensitivo para $4^{\circ}$ espacio -fascículo sensitivo para borde cubital hasta la región proximal al canal de Guyon donde se realizará la trasferencia (-Fig. 9). Una vez localizadas las ramas a usar se realiza una sutura término-terminal con sutura de nylon de 9-0 o Tisucol.

\section{Transferencia de la Rama Sensitiva del Tercer Espacio Interdigital al Fascículo Medial Cubital. Triple Trasferencia}

Esa técnica, descrita por Brown y Mackinnon, ${ }^{16}$ se lleva a cabo para restaurar la sensibilidad del borde cubital de la mano realizándola habitualmente junto con la neurotización motora. 

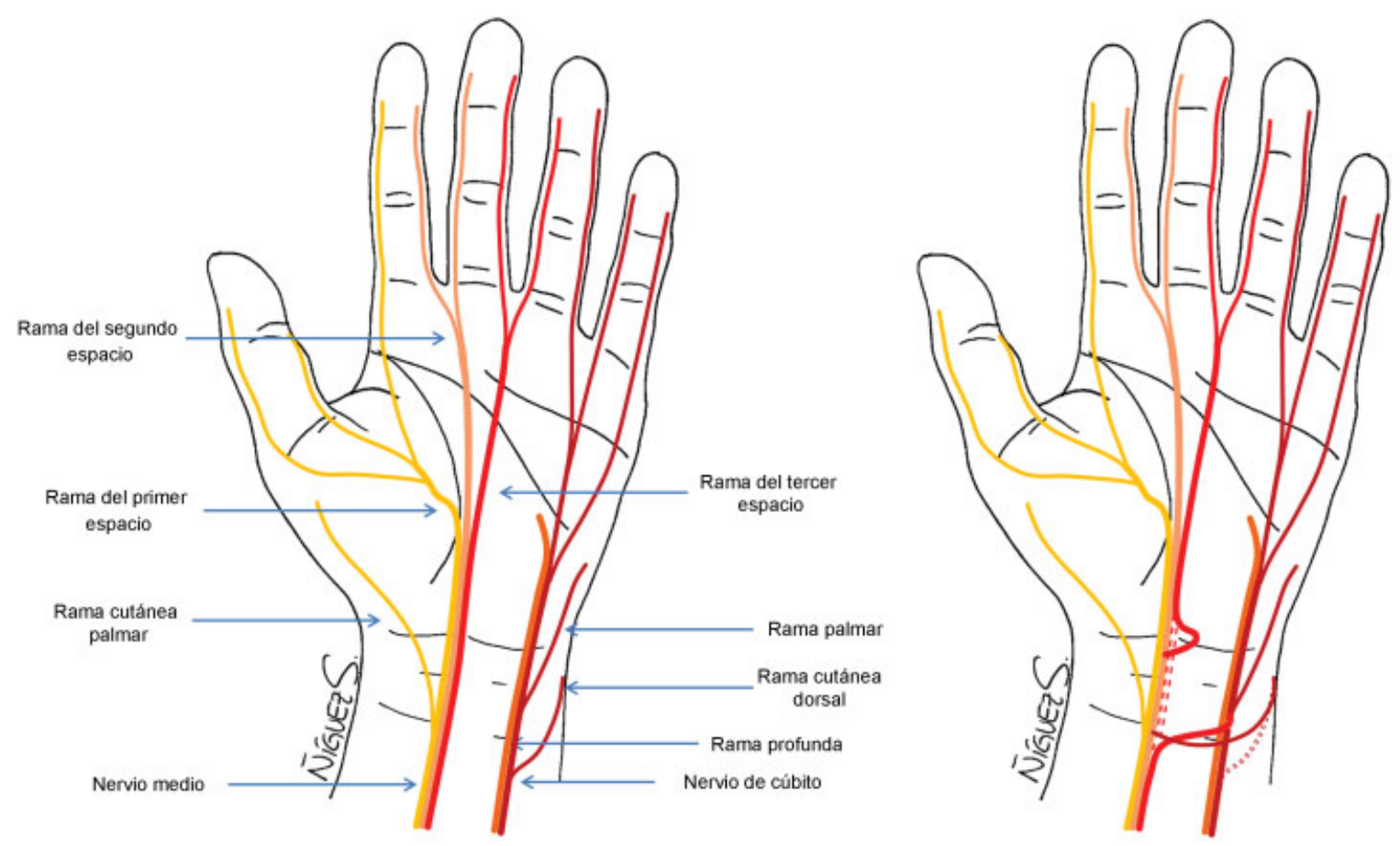

Fig. 10 Transferencia sensitiva de mediano a cubital: fascículo del tercer espacio a fascículo del borde cubital del quinto dedo.
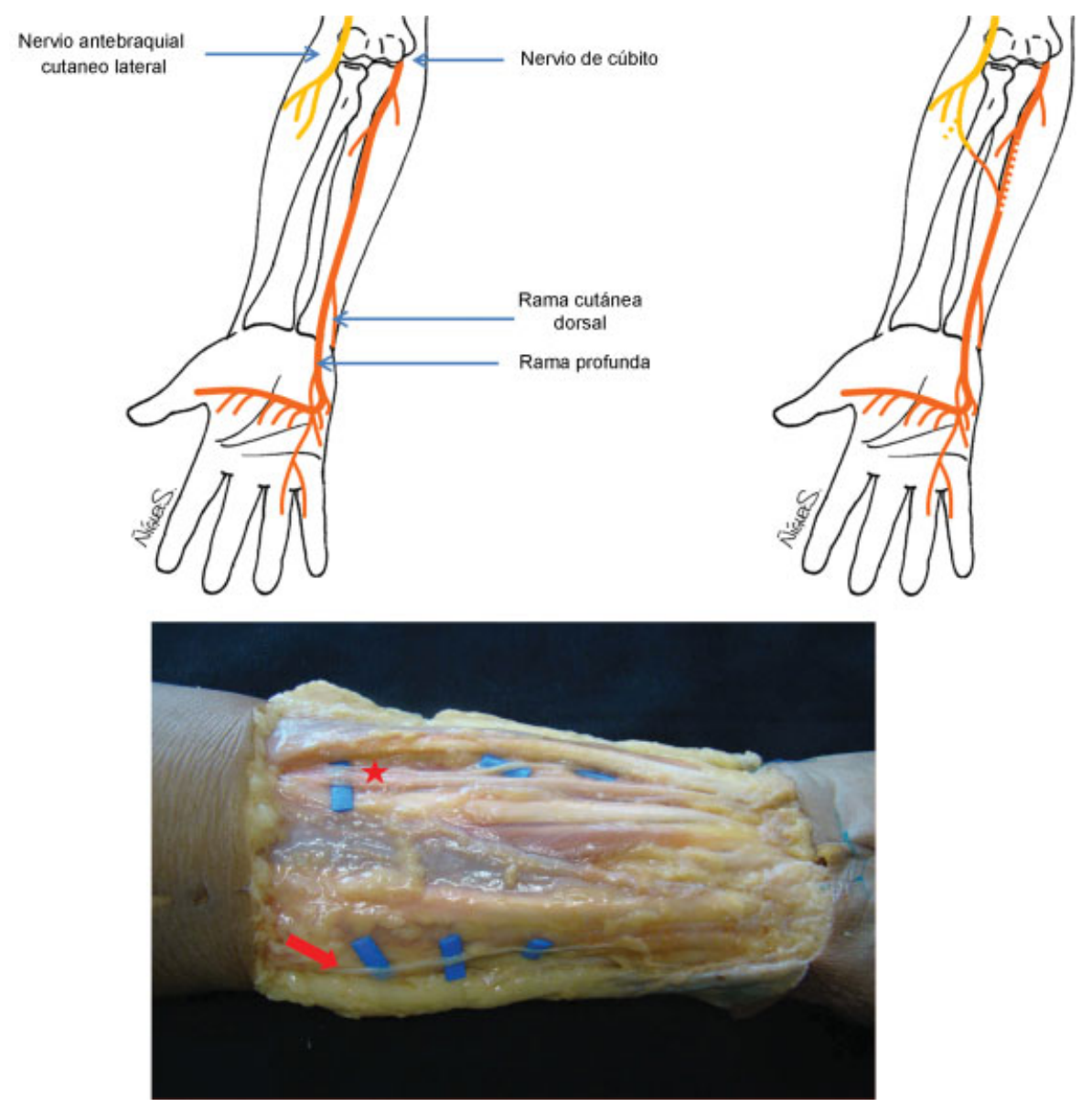

Fig. 11 En la parte superior esquema de la técnica. En la parte inferior disección anatómica donde se aprecia el nervio antebraquial cutáneo lateral (flecha) que se transfiere al fascículo sensitivo del borde cubital (estrella). 
Incisión en tercio distal del antebrazo ampliada a la región del túnel del carpo y canal de Guyon que se abren para evitar neuropatías por compresión. Se realiza endoneurolisis del mediano y cubital trasfiriendo el fascículo más medial del mediano que es el que da la sensibilidad al tercer espacio interdigital al fascículo sensitivo del borde cubital (identificado tras la endoneurolisis desde distal donde están divididos hasta proximal), la disección se prolonga hacia proximal para obtener la longitud adecuada y poder realizar sutura directa con nylon 9/ 0 o Tisucol. En segundo lugar, la rama sensitiva dorsal del nervio cubital se secciona proximalmente y se sutura término-lateral hacia el nervio mediano. En último lugar la porción distal de la rama del tercer espacio, que también se sutura termino-lateral con el nervio mediano adyacente (- Figura 10).

\section{Trasferencia del Nervio Antebraquial Cutáneo Lateral} (Nervio Muculocutáneo) al Nervio Sensitivo Cubital Ruchelsman y col., ${ }^{19}$ describen la transferencia directa del nervio antebraquial cutáneo lateral proximal al nervio cubital en el antebrazo distal para restaurar la función sensitiva en lado cubital de la mano de cuatro niños con déficits sensitivos. Para ello se usa una incisión lineal sobre la cara palmar y radial del antebrazo proximal, distal al pliegue de flexión del codo, y se identifica el nervio profundo a la fascia del antebrazo junto con la vena cefálica. Se disecciona lo más distal posible y se localiza la rama de mayor calibre que se moviliza. A continuación, se realiza una incisión volar y cubital en el antebrazo distal para localizar el nervio cubital, y mediante un túnel subcutáneo, por el que se pasa el nervio antebraquial movilizado previamente, para realizar la neurotización con el nervio cubital tras la disección intraneural y seleccionar el fascículo sensitivo del borde cubital de la mano (-Figura 11).

\section{Referencias}

1 Brunelli GA. Sensory nerves transfers. J Hand Surg [Br] 2004; 29(06):557-562
2 Bertelli JA. Distal sensory nerve transfers in lower-type injuries of the brachial plexus. J Hand Surg Am 2012;37(06):1194-1199

3 Hall EJ, Buncke HJ. Microsurgical techniques to reconstruct irreparable nerve loss. Orthop Clin North Am 1981;12(02):381-401

4 Harris RI. The treatment of irreparable nerve injuries. Can Med Assoc J 1921;11(11):833-841

5 Boyd KU, Nimigan AS, Mackinnon SE. Nerve reconstruction in the hand and upper extremity. Clin Plast Surg 2011;38(04):643-660

6 Brown JM, Mackinnon SE. Nerve transfers in the forearm and hand. Hand Clin 2008;24(04):319-340 v

7 Ducic I, Dellon AL, Bogue DP. Radial sensory neurotization of the thumb and index finger for prehension after proximal median and ulnar nerve injuries. J Reconstr Microsurg 2006;22(02):73-78

8 Ruijs AC, Jaquet JB, Kalmijn S, Giele H, Hovius SE. Median and ulnar nerve injuries: a meta-analysis of predictors of motor and sensory recovery after modern microsurgical nerve repair. Plast Reconstr Surg 2005;116(02):484-494, discussion 495-496

9 Turnbull F. Radial-median anastomosis. J Neurosurg 1948;5(06): 562-566

10 Turnbull F. RESTORARION OF DIGITAL SENSATION AFTER TRANSFECERENCE OF NERVES. J Neurosurg 1963;20:238-240

11 Sunderland $S$. The restoration of median nerve function after destructive lesions which preclude end-to-end repair. Brain 1974;97(01):1-14

12 Bedeschi P, Celli L, Balli A. Transfer of sensory nerves in hand surgery. J Hand Surg [Br] 1984;9(01):46-49

13 Sunderland S. The intraneural topography of the radial, median and ulnar nerves. Brain 1945;68:243-299

14 Bertelli JA, Ghizoni MF. Very distal sensory nerve transfers in high median nerve lesions. J Hand Surg Am 2011;36(03):387-393

15 Strauch B, Lang A. The ten test revisited. Plast Reconstr Surg 2003; 112(02):593-594

16 Mackinnon SE, Nakao Y. Repair and reconstruction of peripheral nerve injuries. J Orthop Sci 1997;2(05):357-365

17 BertelliJA, Ghizoni MF, Loure Iro Chaves DP. Sensory disturbances and pain complaints after brachial plexus root injury: a prospective study involving 150 adult patients. Microsurgery 2011;31(02):93-97

18 Chuang DC. Nerve transfers in adult brachial plexus injuries: my methods. Hand Clin 2005;21(01):71-82

19 Ruchelsman DE, Price AE, Valencia H, Ramos LE, Grossman JA. Sensory restoration by lateral antebrachial cutaneous to ulnar nerve transfer in children with global brachial plexus injuries. Hand (NY) 2010;5(04):370-373 